\title{
Precision Machining
}

\section{FOREWORD}

This special issue of Sādhanā is devoted to Precision Engineering. Recent progress in this field clearly indicates the transition of precision technology to precision science. Dr. Merchant's new theory on the mechanics of metal cutting in 1944 heralded a new approach, moving away from the empirical work of Taylor (1906) that resulted in a new cutting tool material HSS (high speed steel), the Taylor tool life equation $V T^{n}=C$, and the Taylor Gantt bar charts. Gene Merchant's theory was considered the start of a golden era in understanding machining. Merchant's contemporary Professor Milton Shaw introduced new theories in the area of grinding, one of which is the size effect. Both Merchant and Shaw utilised Nobel Laureate Bridgman's work on large plastic flow and fracture to shape their theories that are so well presented here, the size effect being explained in detail. Way back in 1961 Merchant predicted the imminent use of numerical control in machining that has changed manufacturing globally.

Taniguchi predicted new frontiers showing the limitations of the cutting process that needs dislocations for providing a path for shearing to create a chip, and also very sharp tools with radii of $50 \mathrm{~nm}$ or less. The new frontiers of machining are energy processes like lasers, electron beams, and focussed ion beams that do not require sharp tools and dislocations. Intel founder Moore's famous law that chips double their capacity every 18 months continues to be applicable since 1972. The other energy process that brought this about is ultra-violet lithography that only not removes material but provides accretion facility as well.

Free-form optics that help reduce the number and size of lenses is best exemplified from Panasonic's new laser printer using Precitech's machine tools described by Davis in this issue. The need to use natural and synthetic diamonds, a development that uses Bridgman's invention of high pressure presses of over $40 \mathrm{kbars}$ is now surpassed by diamond deposition techniques highlighted by Erik Bauer and his co-authors from Kennametal in their paper in this issue.

The study of wear of bonds is discussed by Professor Jackson. My work discusses the conditions that bring about partial ductile mode grinding, a primary process that drastically reduces secondary processes like lapping and polishing. Dr. Fang discusses the micro-cutting of optical glasses. The final paper by Professor Rahman describes the use of an electrolytic in-process method that dresses metallic bonded diamond grinding wheels, thus bringing about dramatic benefits.

I sincerely thank Professor S Ramaseshan, my former colleague at IIT Madras, Chennai for encouraging me to bring out this Special Issue. I also thank all the authors for their excellent contributions to this issue. I am greatly indebted to Intel (Malaysia) and the Ministry of Science, Technology and the Environment of Malaysia for supporting the innovative research work performed by my group in Malaysia. It was a pleasure working with Dr Gangan Prathap, Editor, Sādhanā and Ms K Shashikala and Mr Riki Krishnan of the Editorial Office of the Academy. Last but not least, my profound thanks go to my stu- 
dents, Dr S Izman, Ms Thet Thet Mon and Ms Deborah Leng for their help in bringing out this issue.

October 2003

V C VENKATESH

Guest Editor 